\title{
Oxygen- and Hydrogen-Isotope Variations in a Firn Core, Eights Station, Western Antarctica ${ }^{1}$
}

\author{
Samuge Epstein and Robert P. Sharp \\ California Institute of Technology, Pasadena, Califormia 91109
}

\begin{abstract}
Oxygen- and hydrogen-isotope analyses of samples from a firn core at Eights station indicate that annual accumulation over a 10-year interval was $39-40 \mathrm{~g} / \mathrm{cm}^{2}$ of water, confirming a condition of relatively heavy precipitation in the Bellingshausen Sea coastal area. The mean $\delta$ value $(-26.6)$ of the $0^{18} / \mathrm{O}^{18}$ ratios is consistent with the relatively low elevation (452 meters) and near-coastal location of Eights station. These data support an earlier suggestion that a cyclical variation of particulate matter recognized in the firn occurs with an approximate 2-year period. No other interrelationship between variations in particulate matter and hydrogen or oxygen isotopes was found.
\end{abstract}

Introduction. James Gliozzi of the Institute of Polar Studies at Ohio State University kindly provided carefully taken samples of a 22 -meter firn core from the Eights station in 1961-1962 [Shimizu, 1964, p. 40; Gliozzi, 1966, p. 1993]. These specimens, totaling 97 , represent a continuous sampling of the core between the depths of 15 and 22 meters in increments ranging from 2.5 to $14 \mathrm{~cm}$. The $\mathrm{O}^{18} / \mathrm{O}^{10}$ and $\mathrm{D} / \mathrm{H}$ ratios were determined in the manner previously described [Craig, 1961a; Epstein et al., 1963, p. 699]. The results are reported in the usual form, the $\delta$ value representing a variation from the ratios of these isotopes found in standard mean ocean water (SMOW) expressed as per mil for oxygen and per cent for hydrogen.

The principal objective of this study was to determine if any consistent relationship exists between isotope variations and the cyclical distribution of particulate matter found within the firn of this core [Taylor and Gliozzi, 1964; Gliozzi, 1966].

Isotope data. Figures 1 and 2 show the results of the isotope analyses. The $0^{18} / 0^{18}$ and $\mathrm{D} / \mathrm{H}$ plots are consistent and yield closely similar interpretations (Table 1). A conservative and preferred interpretation suggests that the 7.0 meters of firn between the depths of 14.95 and 21.95 meters represent 10 years of accumulation. A more liberal interpretation would be that they represent 12 to 13 years.

\footnotetext{
1 Publication 1353, Division of Geological Sciences, California Institute of Technology, Pasadena.
}

As shown in Table 1, these results indicate a mean annual accumulation for the 10-year period of 39 to $40 \mathrm{~g} / \mathrm{cm}^{2}$ of water. Firn densities for conversion to water equivalents were taken from Figure 1 of Gliozzi's [1966, p. 1995] article. A one-year accumulation-stake measurement at this site [Gliozzi, 1966, p. 1994] gives an identical value, but, as shown in Table 1, annual accumulation varies by a factor of more than 2 , so that a one-year measurement can only coincidentally yield the mean annual value.

The isotope data confirm what has already been indicated by accumulation-stake measurements and stratigraphic studies [Shimizu, 1964, pp. 45, 49], specifically that the Bellingshausen Sea coastal region is one of relatively heavy precipitation for Antarctica, but with less of a precipitation shadow at the Eights station than previously thought [Shimizu, 1964, p. 47]. The mean value of the $0^{18} / O^{16}$ ratios for the Eights station $(-26.6)$ is consistent with the relatively low elevation (452 meters) and near-coastal location of this site.

If it is granted that the isotope data properly identify annual layers in the firn, the variation of particulate matter occurs in a cycle of approximately 2 years, as earlier suggested by Taylor and Gliozzi [1964, p. 275] and Gliozzi [1965, p. 1997]. The isotope variations in themselves do not display any recognizable biennial pattern of variations that might in some way be related to events causing a 2-year variation of particulate matter.

The relationship of $\delta D$ to $\delta O^{\text {ss }}$ for Eights station samples is shown in Figure 3. It is con- 


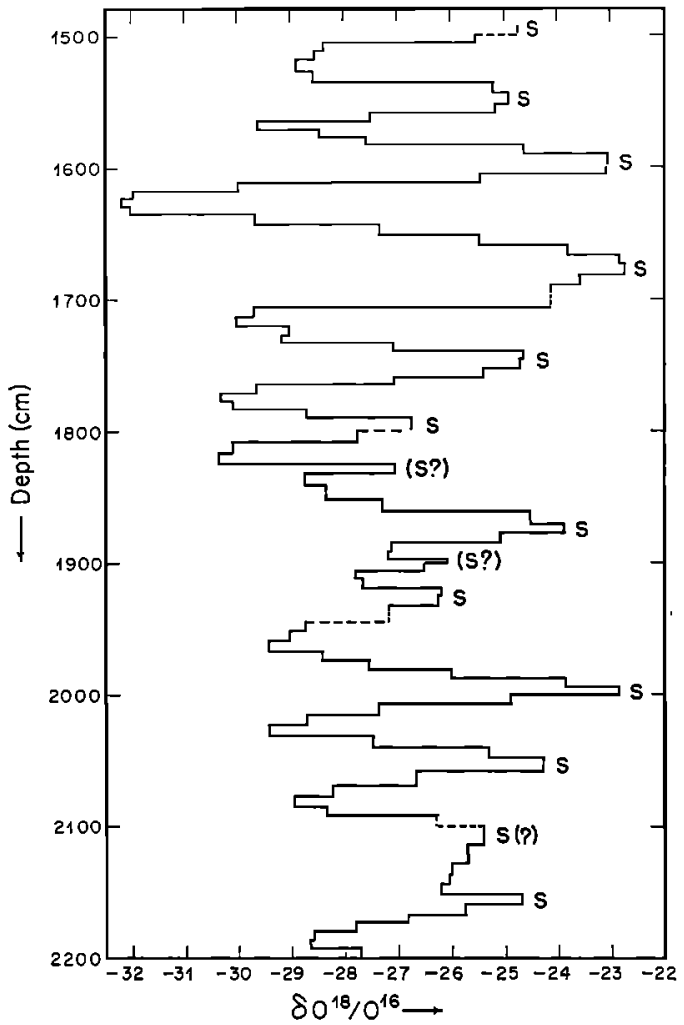

Fig. 1. Oxygen-isotope variations in Eights station firn core. $\mathbf{S}$ is a summer high; $\mathbf{S}($ ?), a questionable high.

sistent with the earlier results of Craig [1961a] and with other antarctic data [Epstein et al., 1965, p. 1812] provided that the latter are adjusted to a comparable base.

As pointed out by Craig [1966] the earlier antarctic $\delta$ values of $E$ pstein et al. [1965] were not properly adjusted for comparison with his data. Raw data from our mass spectrometer must be corrected in the following three ways to make comparisons possible:

1. The $\delta$ values must be adjusted by the addition of -7.3 because of the difference in the $\delta \mathrm{D}$ value of SMOW relative to the working standard used in these analyses.

2. Since the $\mathrm{D} / \mathrm{H}$ ratio of the working standard is lower than the $\mathrm{D} / \mathrm{H}$ ratio of SMOW, the per cent deviation of the $\mathrm{D} / \mathrm{H}$ ratio of the sample from the working standard is greater than the per cent deviation with respect to
SMOW. Therefore, the $\delta \mathrm{D}$ value derived from operation 1 must be divided by 1.073 .

3. This value must then be multiplied by 1.01 because of background and because of an intermixing of sample gas and standard gas known to occur from calibration tests on the mass spectrometer system for these analyses.

In the earlier paper [Epstein et al., 1965] the last two corrections were omitted by oversight. When these 1965 data are divided by 1.063 , they become comparable to Craig's [1961a] results.

As so adjusted, a least-squares calculation using the Eights station, South Pole, and southern California water data [Epstein et al., 1965, p. 1812] gives a relationship of

$$
\delta \mathrm{D}=0.79 \delta 0^{18}+0.46
$$

where $\delta \mathrm{D}$ is reported in per cent relative to SMOW and $\delta O^{18}$ is reported in per mil relative to SMOW.

The slope of this curve is close to Craig's [1961a] value of 0.80 , and the intercept differs

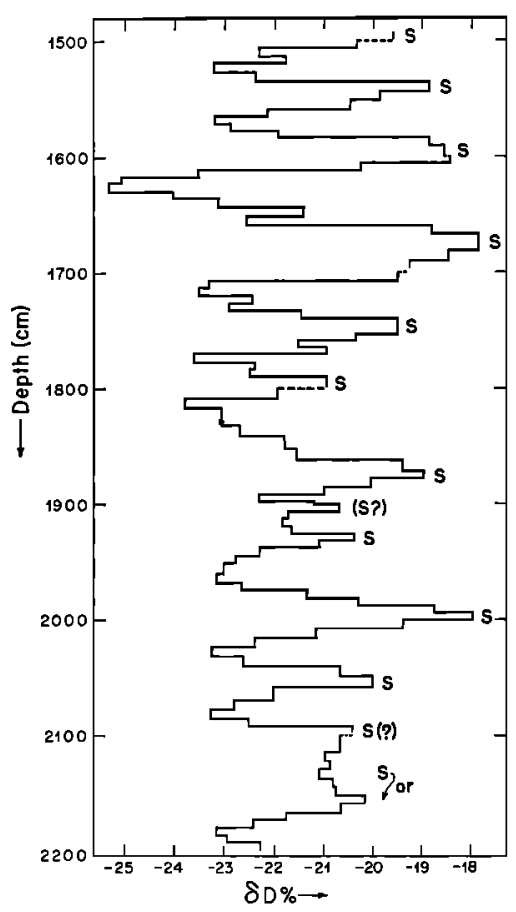

Fig. 2. Hydrogen-isotope variations in Eights station firn core. $\mathrm{S}$ is a summer high; $\mathrm{S}($ ?), a questionable high. 
TABLE 1. Comparison of Oxygen- and Hydrogen-Isotope Interpretations of Annual Layers in Eights Station Firn Core

\begin{tabular}{cccccccc}
\hline & \multicolumn{2}{c}{ Oxygen Isotopes } & \multicolumn{3}{c}{ Hydrogen Isotopes } \\
\hline $\begin{array}{c}\text { Depth, } \\
\text { cm }\end{array}$ & $\begin{array}{c}\text { Interval, } \\
\text { cm }\end{array}$ & $\begin{array}{c}\text { Firn } \\
\text { Density }\end{array}$ & $\begin{array}{c}\text { Water } \\
\text { Equivalence, } \\
\text { g/cm }\end{array}$ & $\begin{array}{c}\text { Depth, } \\
\text { cm }\end{array}$ & $\begin{array}{c}\text { Interval, } \\
\text { cm }\end{array}$ & $\begin{array}{c}\text { Firn } \\
\text { Density }\end{array}$ & $\begin{array}{c}\text { Water } \\
\text { Equivalence, } \\
\text { g/cm }{ }^{2}\end{array}$ \\
\hline $1495-1548$ & 53 & 0.60 & 32 & $1495-1540$ & 45 & 0.60 & 27 \\
$1548-1596$ & 48 & 0.59 & 28 & $1540-1595$ & 55 & 0.59 & 32 \\
$1596-1677$ & 81 & 0.59 & 48 & $1595-1675$ & 80 & 0.59 & 47 \\
$1677-1746$ & 69 & 0.60 & 35 & $1675-1746$ & 71 & 0.60 & 43 \\
$1746-1795$ & 49 & 0.61 & 30 & $1746-1795$ & 49 & 0.61 & 30 \\
$1795-1874$ & 79 & 0.62 & 49 & $1795-1875$ & 80 & 0.62 & 50 \\
$1874-1926$ & 52 & 0.62 & 32 & $1875-1929$ & 54 & 0.62 & 33 \\
$1926-1997$ & 71 & 0.62 & 44 & $1929-1997$ & 68 & 0.62 & 42 \\
$1997-2053$ & 56 & 0.63 & 35 & $1997-2054$ & 57 & 0.63 & 36 \\
$2053-2155$ & 102 & 0.64 & 65 & $2054-2125$ & 71 & 0.64 & 45 \\
& & & & & & Ten-year average & 39 \\
\hline
\end{tabular}

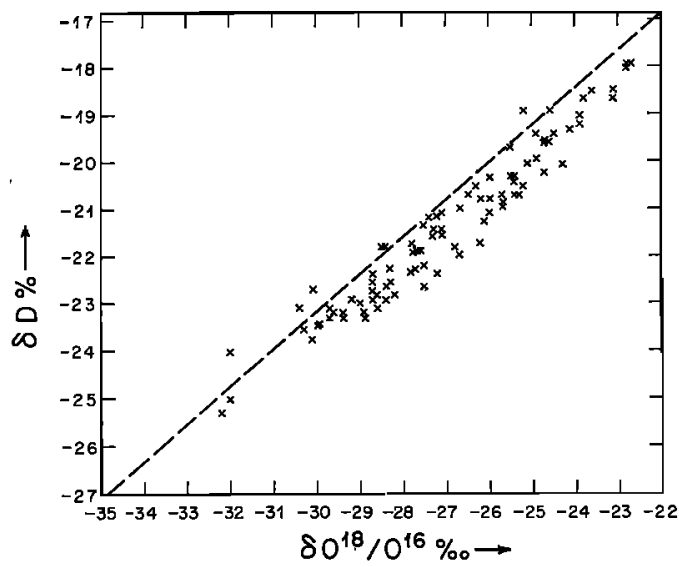

Fig. 3. Plot of hydrogen-isotope ratios against oxygen-isotope ratios in Eights station firn core. Dashed line represents the relationship obtained from the corrected data of Epstein et al. [1965].

TABLE 2. Values for Standards (Relative to SMOW)

Number of determinations are in parentheses.

\begin{tabular}{lcc}
\hline \multicolumn{1}{c}{ Standards } & $\delta \mathrm{O}^{18}, \% \circ$ & $\delta \mathrm{D}, \%$ \\
\hline NBS-1 & $-7.89(4)$ & $-4.76(3)^{*}$ \\
NBS-1A & $-24.30(4)$ & $-18.46(2) \dagger$ \\
LJ-2 & & $-0.23(2)$ \\
\hline
\end{tabular}

* By definition (see Craig, 1961b).

$\dagger$ This value is for a single aliquot of NBS-1A received from National Bureau of Standards. Another aliquot gave a less negative result of -18.23 . The cause of this difference is unknown but may come from the handling of the samples. by about $0.5 \%$. A slope of 7.9 and an intercept of 4.6 are obtained if the $\delta \mathrm{D}$ values are expressed as per mil instead of per cent. Since a considerable scatter of points exists in Craig's data as well as ours and since there is as yet no a priori reason why a single precise relationship between $\delta \mathrm{D}$ and $\delta \mathrm{O}^{18}$ must exist for all meteorological water samples, these differences are acceptable for the present.

Reported here (Table 2) are some newly determined $\delta$ values for the National Bureau of Standards, NBS-1 and NBS-1A, water samples and one of Craig's standards, LJ-2.

Acknowledgments. This work was supported by National Science Foundation grant GA-98 and used a mass spectrometer constructed under Atomic Energy Commission contract AT (04-3)427.

\section{References}

Craig, H., Isotopic variations in meteoric waters, Science, 183(3465), 1702-1703, 1961a.

Craig, H., Standard for reporting concentrations of deuterium and oxygen 18 in natural waters, Science, 198(3467) 1833, $1961 b$.

Craig, H., Discussion of paper by S. Epstein, R. P. Sharp, and A. J. Gow, 'Six-year record of oxygen and hydrogen isotope variations in South Pole firn,' J. Geophys. Res., 71(4), 1287, 1966.

Epstein, S., R. P. Sharp, and I. Goddard, Oxygenisotope ratios in antarctic snow, firn, and ice, J. Geol., $71(6), 698-720,1963$.

Epstein, S., R. P. Sharp, and A. J. Gow, Six-year record of oxygen and hydrogen isotope variations in South Pole firn, J. Geophys. Res., 70(8), 1809-1814, 1965. 
Gliozzi, James, Quantitative analysis of microparticles in two antarctic firn cores, J. Geophys. Res., 71(8), 1993-1998, 1966.

Shimizu, Hiromu, Glaciological studies in West Antarctica, 1960-1962, Antarctic Snow and 1ce Studies, Antarctic Res. Ser., vol. 2, edited by Malcolm Mellor, pp. 37-64, American Geophysical Union, Washington, D. C., 1964.
Taylor, L. D. and J. Gliozzi, Distribution of particulate matter in a firn core from Eights station, Antarctica, Antarctic Snow and Ice Studies, Antarctic Res. Ser., vol. 2, edited by Malcolm Mellor, pp. 267-277, American Geophysical Union, Washington, D. C., 1964.

(Received May, 26, 1967.) 